\title{
Homo sapiens and milk: a valuable food in the past and in the future
}

\author{
Leone Arsenio - Silvana Caronna $\cdot$ Federico Cioni \\ Elisabetta Dall'aglio
}

Received: 5 August 2009/Accepted: 6 October 2009/Published online: 13 July 2010

(C) Springer-Verlag 2010

\begin{abstract}
Milk is a food with a very high biological value, essential in the early stages of life, and has been used to produce ricotta and other cheeses in the Mediterranean area for at least for the last 6,000 years. From a nutritional point of view, in addition to a high water content, milk also contains glucids, proteins of a high biological quality, lipids, vitamins and minerals in highly absorbable forms. In terms of evolution, cholesterol also plays an important role in the activation and propagation of the hedgehog signaling cascade, which is responsible for the differentiation and development of the central nervous system. Finally, the authors analyze its potential as a vector of alimentary supplements, making this food fundamental for human nutrition and the future of Homo sapiens.
\end{abstract}

Keywords Milk · Homo sapiens · Evolution

\section{Introduction}

Milk is a food of high biological value: in the first period of life is the most natural and important nutrient, the only able to double the weight of the infant in the first 6 months of life and enable a strong cerebral development after birth. The suckle instinct, a mammals' characteristic, appeared with the development of the cerebral limbic system approximately 200 million years ago; however, this has grown considerably over the last 65 million years. In women, breasts develop independently of lactation and do not decrease in size until disappear after lactation, as in

L. Arsenio · S. Caronna · F. Cioni $(\bowtie) \cdot$ E. Dall'aglio

SSD Malattie del Ricambio e Diabetologia, Azienda

Ospedaliero, Universitaria di Parma, Parma, Italy

e-mail: federicocioni@mattioli1885.com other mammals. Moreover, man is the only mammal to use milk from other species for nutrition, even after infancy. Archeologists at the Universities of Oxford and Cambridge and researchers from the local superintendency recently discovered one of the most ancient Mediterranean "farms", dating back to the copper age (approximately 6,000 years ago): the archeological site at Troina, in Sicily. Analyzing the findings, particularly vases, the researchers discovered not only that the ancient inhabitants of the site consumed large quantities of milk, but they also knew techniques of preservation of milk and were already able to produce two different types of cheese: ricotta and "tuma" a type of nonmatured pecorino.

\section{Nutritional aspects}

Milk, produced by secretion from the mammary gland, is a complex liquid that contains, besides water (87-88\%), glucids (lactose $4.8 \%$ ), which are utilized quickly and are useful to the nervous system, proteins $(3.3 \%)$ of a high biological quality, lipids (3.5\%), vitamins (particularly A, $\mathrm{D}, \mathrm{B}_{2}$ ) and minerals (calcium and phosphorus in highly absorbable forms).

Glucose and galactose originate from the lactose in milk: glucose is an important source of energy and galactose is indispensable for sphingolipid synthesis. Sphingolipides are cerebrosides components, essential for the development and functioning of the cerebral neurons, in the myelin sheaths of the axons.

Man has a natural ability to hydrolyze lactose in glucose and galactose, which is then lost on weaning. In populations with a long history of sheep farming, a mutant form of the lactase gene remains active throughout adult life. This genetic modification has been linked to mutations of 
single bases of DNA control regions, controlling the gene: these mutations differ according to the geographic regions [1]. Man's natural predisposition to hydrolyze lactose in glucose and galactose is reduced approximately in $40 \%$ of the general population, this seeming to be mainly associated with intestinal pathologies rather than a genetic deficiency of lactase $[2,3]$.

Protein content [4] comprises casein $(80 \%)$ and lactalbumin, lactoglobulins, peptones and immunoglobulins $(20 \%)$. The caseins, dispersed in a colloidal solution in the form of micelles, include the kappa, beta, alphaS1 and alphaS2 caseins; they do not coagulate except for acidification or curdling, thus giving rise to cheese formation. Lactoferrin has an antibacterial activity and carries out an important role in iron absorption. During casein digestion, several bioactive peptides are released. They have regulatory effects on several functions, such as nutrient absorption, minerals (calcium) transport in the gut (phosphopeptides); amino acids transport, intestinal fluids balance, gastrointestinal motility and hormones (insulin, somatostatin) secretion (beta-casomorphin); immunostimulation (fragments of alphaS1 and betacasein); antihypertensive effects (casokinine).

Milk's amino acid spectrum is of high quality, with an essential amino acids supply similar to that of beef and much better than that of wheat. In particular, milk is a good source of branched-chain amino acids (valine, leucine, isoleucine) (BCAA) (Table 1) [5]. One particular aspect of some amino acids metabolism is their capacity to modify neurotransmitter levels in the central nervous system. In fact, physical activity causes increased BCAA oxidation in muscle, reducing their plasma levels. An increase in free tryptophan blood levels also occurs; tryptophan is not linked to albumin, and, therefore, is able to cross biological barriers and to spread via a common "carrier". Finally, a significant increase in ammonia levels can be observed when substantial physical activity is performed. All those conditions increase tryptophan trespassing across hematoencephalic barrier: tryptophan, as precursor to serotonin synthesis, induces a significative increase in brain's serotonin levels. Higher concentrations of serotonin result in mood disturbances, reduced concentration and drowsiness. This phenomenon is connected with the existence of a single competitive "carrier" (L-transport system, leucinepreferring) used to carry tryptophan and BCAA across hematoencephalic barrier: consequently, during exercise, the tryptophan molecule flow, which has a higher concentration, prevails over that of the BCAA, which are reduced. In addition, increased blood concentration of ammonia, which is also present in the cerebral liquor and structures, leads to an increase in glutamine, the mobile and non-toxic resource of ammonia radicals; glutamine transfers in the opposite direction, from liquor to blood, using a "carrier" similar to that used by BCAA; therefore circulating tryptophan finds higher levels of carriers available for inverse transport. In conclusion, an increased flow of tryptophan results in greater serotonin production, followed by early appearance of fatigue. On the other hand, a considerable BCAA supplementation would reduce the rise in plasma ammonia, hinder the passage of tryptophan and ultimately excessive serotonin production and would therefore reduce and delay the appearance of the sensation of fatigue, improving mental performance and preventing overfitness symptoms [4].

Milk's lipid phase [4] is made up of neutral lipids (glycerides) which represent $98 \%$ of the total, polar lipids (phospholipids), which represent approximately $1 \%$ of the total and various lipidic substances, including liposoluble vitamins. Saturated fatty acids (FA) represent approximately $2 / 3$ of the total, with a significant presence of shortchain FAs, which pass into the liver direct through the portal vein without entering into systemic circulation, and stearic acid, which is desaturated in humans to oleic acid and for this reason may be included, from a functional viewpoint, among unsaturated fatty acids. The unsaturated FAs include oleic acid in particular. The FAs which are definitively considered arthrogenous are $<60 \%$. A considerable quantity of unsaturated fatty acids is constituted by oleic acid, whereas the linoleic and $\alpha$-linolenic acids are present in much reduced concentrations (respectively approximately 80 and $50 \mathrm{mg}$ per $100 \mathrm{~g}$ of whole milk). Among polyunsaturated acids, the CLAs (conjugated linolenic acid) isomers series have generated considerable interest. CLAs are formed from linoleic acid in ruminants' stomachs by specific microorganism's action. They are present mainly in milk, milk-based food and beef and their quantity depends on seasonality, farming conditions and the microbial flora in the rumen. The cis-9 trans-11 isomer carries out anticancer activity in different types of tumour [6], and a protective effect at the onset of atherosclerotic diseases [7] and obesity [8].

The cholesterol content is moderate $(12.3 \mathrm{mg} / 100 \mathrm{~g})$. The free form of cholesterol is the basis for the synthesis of biliary acids, vitamin $\mathrm{D}$, steroid hormones and metabolic mediators, such as oxysterol; it takes part in cerebral neurons development and in the process of learning and memory. It is a constitutive part of cell membranes and influences the content of other lipids inside the membranes, especially sphingomyelin, making cholesterol a fundamental metabolic mediator for the activation and propagation of the hedgehog signaling cascade, responsible for central nervous system differentiation and development. In mammals, three hedgehog signaling cascades are activated by cholesterol: Sonic, Indian, and Desert. In fact, during initial embryonic development, the cells are not differentiated and most of the neural cells are multipotent; the 
Table 1 Requirements of amino acids at different ages compared with the supply in cow's milk, beef and wheat

\begin{tabular}{|c|c|c|c|c|c|c|c|}
\hline \multirow[t]{2}{*}{ Essential amino acids } & \multicolumn{4}{|c|}{ Amino acid requirements ${ }^{\mathrm{a}}$} & \multicolumn{3}{|c|}{ Amino acids supplied by different foods } \\
\hline & $\begin{array}{l}\text { Babies } \\
\text { (1 year) }\end{array}$ & $\begin{array}{l}\text { Infants } \\
\text { (2-5 years) }\end{array}$ & $\begin{array}{l}\text { Children } \\
\text { (10-12 years) }\end{array}$ & Adult & Cow’s milk & Beef & Wheat \\
\hline Histidine & 165 & 125 & 115 & 100 & 169 & 213 & 120 \\
\hline Isoleucine & 290 & 190 & 180 & 80 & 294 & 301 & 232 \\
\hline Leucine & 580 & 440 & 290 & 120 & 594 & 507 & 379 \\
\hline Lysine & 415 & 390 & 290 & 100 & 488 & 556 & 159 \\
\hline Methionine + cystine & 265 & 165 & 145 & 105 & 206 & 249 & 225 \\
\hline Phenylalanine + thyroxine & 450 & 415 & 145 & 120 & 638 & 500 & 462 \\
\hline Threonine & 270 & 225 & 180 & 55 & 275 & 287 & 192 \\
\hline Tryptophan & 165 & 75 & 55 & 30 & 88 & 70 & 68 \\
\hline Valine & 345 & 230 & 165 & 80 & 400 & 313 & 270 \\
\hline \multicolumn{8}{|l|}{ Total } \\
\hline+ Histidine & 2,875 & 2,245 & 1,520 & 795 & 3,150 & 2,995 & 2,105 \\
\hline -Histidine & 2,715 & 2,120 & 1,415 & 695 & 2,981 & 2,780 & 1,990 \\
\hline
\end{tabular}

${ }^{a} \mathrm{FAO} / \mathrm{OMS}$ : calculated from values in $\mathrm{mg} / \mathrm{g}$ of protein (Protein $\mathrm{N} \times 6.25$ ), rounded up to the nearest $5 \mathrm{mg}$

primary neuroectoderm divides into, giving rise to telencephalon, diencephalon, mesencephalon and rhomboencephalon: DNA transcription and signal molecules (morphogenes), including cholesterol, are essential for providing information about neuronal differentiation and positioning. During pregnancy, adding to the endogenous fetal cholesterol production, placenta replenishes the fetus with a total amount of approximately $8 \mathrm{~g}$. The lipid profile of the umbilical cord has an LDL-c level that is approximately one-third compared with that of an adult, and is rich in triglycerides and lacking in cholesterol, whereas the HDL-c level is approximately half, with many more HDL lipoproteins rich in ApoE, which is the dominant transporter towards the tissues of the fetus and of the rapidly growing newborn, especially at central nervous system level [9]. The hedgehog signaling cascades also play an important role in the brain after birth and in adult life [10]. Nerve impulses are transmitted along neuronal axons one hundred times faster when axons are sheathed in myelin and the myelin is deposited around the axons like insulating tape, wrapping itself around the axons up to 150 times between one node and the next. The myelin is produced like a laminar structure from two types of glial cells: the oligodendrocyte, shaped like an octopus, sheaths the central nervous system, whereas the myelin of each internode in the peripheral nervous system is formed by a single Schwann cell, in the shape of a sausage. The speed of conduction is greater in relation to the thickness of the insulation: the optimal ratio between unsheathed axon diameter and fiber total diameter (axon + myelin) is 0.6. The wrapping occurs at different ages: at birth, the myelin predominates only in some regions of the brain, it expands in bursts and in some regions it is not completely deposited until 25-30 years of age; during growth, myelinization generally proceeds in waves starting from the posterior cerebral cortex and proceeding towards the frontal part. Myelinization occurs last in the frontal lobes, which are responsible for planning and evaluation capacity. Myelinization is probably completed only at the start of adulthood. Glia can regulate myelinization in relation to the traffic of impulses transmitted along axons. The speed of transmission, secondary to myelinization, is different in relation to the distances between the cerebral centers: in the adult, $30 \%$ of axons are still without myelin. This variability means that it is possible to coordinate the speed of transmission, strengthening the connections in specific neuronal circuits and influencing cerebral functions [11]. A recent finding, made at Pinnacle Point in South Africa is particularly interesting, as it backdates the first appearance of esthetic consciousness to 164,000 years ago. Some fragments of red ochre, with clear signs of use, i.e. marks made by deliberate slashes suggesting body painting and a symbolic use of color, were found at the site, supporting the hypothesis of symbolic thought and articulated language expression by those ominides. Beside the ochre, there was a pile of the remains of meals based on molluscs and crustaceans proving that Homo sapiens moved to this marine region, probably to escape from a land environment made poor and hostile due to a glaciation lasting approximately 70,000 years (from 195,000 to 125,000 years ago) [12]. The scientific hypothesis is that the two phenomena are linked and that the diet based on crustaceans and molluscs, rich in cholesterol and polyunsaturated fatty acids, influenced brain evolution.

All these data support the importance of contemporary presence in milk of cholesterol, phospholipids and 
galactose, essential nutrients for the progressive myelinization of the neuron axons and for CNS development.

Minerals make up approximately $0.7-0.8 \%$ of milk and include several elements, such as potassium, sodium, magnesium, phosphorus, chlorides, sulfates and calcium and some trace elements, such as zinc, silicon, copper, iron, aluminum, manganese, cobalt, fluorine and iodine. The amount of phosphorus, potassium, magnesium and calcium is elevated; 11 of milk contains approximately $1,200 \mathrm{mg}$ of calcium, $910 \mathrm{mg}$ of phosphorus and $120 \mathrm{mg}$ of magnesium, with an optimum calcium/phosphorus ratio, required for the absorption of calcium and whole milk contains significant concentrations of vitamin D3 (Table 2) [5]. A high supply of calcium from milk and diary products in infancy and adolescence can ensure optimal bone mineralization and prevent osteoporosis, bearing in mind that one cup of milk provides approximately $30 \%$ of the calcium daily requirement, according to LARN [13].

\section{Milk as a vector of alimentary supplements}

Widespread consumption of diet supplements is the result of numerous epidemiological investigations that demonstrated significative relationships between nutritional mistakes and chronic-degenerative diseases, suggesting the need to increase the intake of some important trace nutrients (vitamins, minerals, antioxidants, etc.). A recent study presented at Cosmofarma 2008, sponsored by FederSalus (An Italian Federation which unites the companies producing health products) showed that almost one out of three Italians commonly uses nutritional supplements, in 6 out of 10 cases from more than 2 years. The list of regularly purchased products is long: vitamin and mineral supplements (52.5\%) are at the top of the list, followed by prebiotics (36\%) and sports energy supplements based on the vitamins, mineral salts, amino acids and proteins (14.4\%), these being mostly appreciated by men (23 against $9.9 \%$ of women). Approximately, two-thirds of the consumers were women (mean 66\%, increasing to $71.6 \%$ in the north-west), with a medium-high level of education (51.7\%). Furthermore, $42.1 \%$ play sport and $39.1 \%$ habitually follow a healthy diet. However, a recent Cochrane metanalysis of clinical studies [14] does not show any

Table 2 Mean content of calcium, phosphorus and vitamin D of milk $(\mathrm{mg} \times 100 \mathrm{~g}$ of food $)$

\begin{tabular}{lll}
\hline & Whole milk & Skimmed milk \\
\hline Calcium (mg) & 120 & 123 \\
Phosphorus (mg) & 92 & 97 \\
Calcium/phosphorus ratio (Ca/P) & $1: 0.76$ & $1: 0.78$ \\
Liposoluble vit. D (ng) & 63 & Trace \\
\hline
\end{tabular}

significant effects of antioxidants supplementation on mortality, either in healthy or pathological subjects. In contrast, a significant increase in mortality following supplementation with beta-carotene, vitamin A and vitamin $\mathrm{E}$, can be observed. The limits of this metanalysis are numerous: doses, times and procedures used are different and variable. In particular, authors took into consideration only the antioxidants taken as a supplement and not those added to food. Food is much more complex and bioavailability and efficacy of trace nutrients contained in it should have to be evaluated in a specific way.

From this point of view, milk can play a very important role as a vector of supplements. In fact, complexity and nutritional stability of milk makes it an ideal vehicle for the supply of important trace nutrients to improve nutritional quality and to prevent the chronic-degenerative diseases widespread, typical of the industrialized world. Recent studies confirmed this perspective: for example, the addition of co-enzyme Q10 and omega-3 to milk significantly increases plasma antioxidant capacity [15] and can improve lipid balance assessment [16-18].

\section{Conclusions}

In conclusion, milk has almost unique characteristics, both for its nutrient content (notable quantities of good quality amino acids, especially BCAA, complete lipid spectrum, high content of lactose and thus of galactose, richness in trace nutrients, both minerals and vitamins, etc.), both for the ease of ingestion, the high degree of digestibility, the multiple uses (breakfast or meals or as a snack) and for the ability to act as a base for trace elements enrichment and supplementation. Therefore, it can be considered a food which played a fundamental role in the past and can still have a brilliant future in Homo sapiens nutrition.

Conflict of interest None.

\section{References}

1. Enattah NS et al (2008) Independent introduction of two lactase persistent alleles into human populations reflects different history of adaptation to milk culture. Am J Human Genet 82:57-72

2. Rossi M, Maiuri L (1997) Lactase persistence versus decline in human adults: multifactorial events are involved in down-regulation after weaning. Gastroenterology 112:1506-1514

3. Rusynyk RA, Still CD (2001) Lactose intolerance. J Am Osteopath Assoc 101(4 suppl Pt 1):S10-S12

4. Arsenio L (2007) Alimentazione, clima ed evoluzione dell'uomo. Mattioli 1885, Fidenza (PR), pp 121-128

5. Del Toma E (2003) Il latte. Alimentazione e Benessere 1:2-6

6. Larsson SC, Begkvist L, Wolk A (2005) High-fat dairy food and conjugated linoleic acid intakes in relation to colorectal cancer 
incidence in the Swedish Mammography Cohort. Am J Clin Nutr 82:894-900

7. Arbones-Mainar JM, Navarro MA, Guzman MA et al (2006) Selective effect of conjugated linoleic acid isomers on atherosclerotic lesion development in apolipoprotein E knockout mice. Atherosclerosis 189(2):318-327

8. Bracco U (2002) CLA: gli isomeri coniugati dell'acido linoleico. Alimentazione Prev 2:53-57

9. Fujita $\mathrm{H}$ et al (2008) Heterogeneity of high-density lipoprotein in cord blood and its postnatal change. Clin Chim Acta 389:93-97

10. Charytoniuk D, Porcel B, Rodríguez Gomez J, Faure H, Ruat M, Traiffort E (2002) Sonic hedgehog signalling in the developing and adult brain. J Physiol (Paris) 961-2:9-16

11. Fields RD (2005) Myelination: an overlooked mechanism of synaptic plasticity? Neuroscientist 11:528-531

12. Marean C et al (2007) Early human use of marine resources and pigment in South Africa during the Middle Pleistocene. Nature $\mathrm{XV}: 449$

13. INRAN (Istituto Nazionale di ricerca per gli Alimenti e la Nutrizione) (1996) LARN Livelli di assunzione giornaliera raccomandati di nutrienti per la popolazione italiana, Revisione
14. Bjelakovic G, Nikolova D, Gluud LL, Simonetti RG, Gluud C (2008) Antioxidant supplements for prevention of mortality in healthy participants and patients with various diseases. Cochrane Database Syst Rev 2:CD007176

15. Arsenio L, Caronna S, Dall'Aglio E et al (2008) Effect of antioxidant-enriched foods on plasma coenzyme $\mathrm{Q}_{10}$ and total antioxidant capacity. Eur J Lipid Sci Technol 110 (in press)

16. Visioli F, Rise P, Bosisio R, Sirtori C, Galli C (2007) Omega 3 -fortified milk. Modulation of colesterolemia in dyslipidemic patients. Nutrafoods 62:15-19

17. Baro L, Fonolla J, Pena JL et al (2003) N-3 fatty acids plus oleic and vitamin supplemented milk consumption reduces total and LDL cholesterol, homocysteine and levels of endothelial adhesion molecules in healthy humans. Clin Nutr 22:175-182

18. Carrero JJ, Baro L, Fonolla J et al (2004) Cardiovascular effects of milk enriched with omega- 3 polyunsaturated fatty acids, oleic acid, folic acid, and vitamins $\mathrm{E}$ and $\mathrm{B} 6$ in volunteers with mild hyperlipidemia. Nutrition 20:521-527 